\title{
Avaliação de estudantes surdos e deficientes auditivos sob um novo paradigma: Enem em Libras
}

\author{
The assessment of deaf and hearing-impaired students under a new \\ paradigma: ENEM in Libras
}

\section{Evaluación de estudiantes sordos y deficientes auditivos bajo un nuevo paradigma: Enem en Libras}

\section{${ }^{*}$ Rogério Diniz Junqueira}

\author{
Pesquisador do Instituto Nacional de Estudos e Pesquisas Educacionais Anísio Teixeira (Inep), Brasília, \\ Distrito Federal, Brasil. \\ rogeriodinizjunqueira@gmail.com
}

\section{** Cristina Broglia Feitosa de Lacerda}

Professora doutora da Universidade Federal de São Carlos (UFSCar), São Carlos, São Paulo, Brasil. cbflacerda@gmail.com

\section{Recebido: 21 de agosto de 2017}

Aprovado: 13 de setembro de 2018

\section{RESUMO}

O artigo trata da necessidade, pertinência e legitimidade do desenvolvimento de instrumentos específicos em Língua Brasileira de Sinais (Libras) e em Português como segunda língua para avaliar o desempenho de estudantes com surdez ou deficiência auditiva no âmbito do Exame Nacional do Ensino Médio (Enem). Considera os debates da Comissão Assessora de Especialistas em Educação Especial nomeada pelo Inep acerca da legislação brasileira, das especificidades envolvidas na escolarização de surdos e dos desafios inerentes à necessidade de lhes garantir acessibilidade em exames de larga escala. Pondera que, mesmo com o apoio de intérpretes, submeter participantes com surdez que tenham Libras como primeira língua a uma prova escrita em português configura um quadro de acessibilidade insuficiente e representa uma quebra de isonomia. Além disso, uma vez que os cálculos das médias do Enem são feitos com base na Teoria da Resposta ao Item (TRI), a falta de acessibilidade compromete os parâmetros psicométricos do exame. Por isso, a oferta de provas devidamente traduzidas em Libras, disponibilizadas em vídeo, em formato digital e em computadores individualizados, demonstra ser, no estágio atual das discussões sobre acessibilidade, um meio justo, seguro e apropriado para assegurar direitos, equidade e isonomia ao exame. O Enem em Libras representa uma mudança de paradigma na avaliação de pessoas que têm a Libras como primeira língua, configurando um reconhecimento dos direitos linguísticos dessa população. Os resultados de sua aplicação precisarão ser conhecidos e devidamente analisados com vistas a garantir 0 aprimoramento contínuo da política de acessibilidade do exame. 
http://dx.doi.org/10.5902/1984686X28732

Palavras-chave: Estudantes surdos; Libras; Exame Nacional do Ensino Médio (Enem).

\section{ABSTRACT}

This paper addresses the necessity, adequacy and legitimacy of developing specific instruments translated to Brazilian Sign Language (Língua Brasileira de Sinais - Libras) and adapted to Portuguese as a second language, to assess the deaf and hearing-impaired students' performance at the National Exam of Upper Secondary Education (Exame Nacional do Ensino Médio - ENEM). It investigates the discussions of Inep's appointed Advisory Committee on Special Education (Comissão Assessora de Especialistas em Educação Especial) regarding the Brazilian laws, the specificities of teaching the deaf, and the challenges of guarantying their accessibility in large-scale exams. It considers that, even supported by interpreters, put deaf participants, whose first language is Libras, through a Portuguese written test leads to lack of accessibility and represents a violation of equitable treatment. It remarks that, since Enem's calculation of the mean scores is based on the Item Response Theory (IRT), the lack of accessibility compromises the psychometric parameters of the exam; therefore, the use of a material, which is dutifully translated, available in video, digitally-formatted and individualized, seems to be, at this point of the discussions about accessibility, a fair, proper and safe way to ensure rights, equity and isonomy. The Enem in Libras signifies a shift in paradigm in the assessment of those whose first language is Libras, representing an acknowledgment of their linguistic rights. The achievements in doing so should be known and dully analyzed in order to ensure the lasting betterment of the exam's accessibility policies.

Keywords: Deaf students; Brazilian Sign Language (Libras); National Exam of Upper Secondary Education (Enem).

\section{RESUMEN}

El artículo trata de la necesidad, pertinencia y legitimidad del desarrollo de instrumentos específicos en Lengua Brasileña de Señales (Libras) y el portugués como segunda lengua para evaluar el rendimiento de los estudiantes con sordera o discapacidad auditiva en el marco del Examen Nacional de Enseñanza Media (Enem). En el marco de la legislación brasileña, las especificidades involucradas en la escolarización de sordos y de los desafíos inherentes a la necesidad de garantizarles accesibilidad en exámenes a gran escala, considera los debates de la Comisión Asesora de Especialistas en Educación Especial nombrada por el Inep sobre la legislación brasileña, considera que, incluso con la ayuda de intérpretes, presentes participantes con pérdida de libras que tienen como primera lengua a una prueba escrita en portugués configura un marco accesibilidad insuficiente y representa una violación de la igualdad de la audición. Además, dado que los cálculos de las medias del Enem se basan en la Teoría de la Respuesta al Item (TRI), la falta de accesibilidad compromete los parámetros psicométricos del examen. Por eso, la oferta de pruebas debidamente traducidas en Libras, disponibles en video, en formato digital y en computadoras individualizadas, demuestra ser, en la etapa actual de las discusiones sobre accesibilidad, un medio justo, seguro y apropiado para asegurar derechos, equidad e isonomía al el examen. El Enem en Libras representa un cambio de paradigma en la 
http://dx.doi.org/10.5902/1984686X28732

evaluación de personas que tienen la Libras como primera lengua, configurando un reconocimiento de los derechos lingüísticos de esa población. Los resultados de su aplicación necesitarán ser conocidos y debidamente analizados para garantizar el perfeccionamiento continuo de la política de accesibilidad del examen.

Palabras clave: Estudiantes sordos; Lenguaje Brasileña de Señales (Libras); Exame Nacional do Ensino Médio (Enem).

\section{Introdução}

Há anos, a comunidade surda brasileira reivindica a oferta de exames nacionais, concursos e vestibulares em Língua Brasileira de Sinais (Libras). O Instituto Nacional de Estudos e Pesquisas Educacionais (Inep) anunciou que na edição do ano de 2017 do Exame Nacional do Ensino Médio (Enem), além dos recursos e serviços tradicionalmente ofertados no atendimento especializado a pessoas com deficiência, seria oferecida, em processo experimental, uma versão traduzida em Libras. A videoprova do Enem em Libras, disponibilizada em formato digital e em computadores individualizados, está organizada como as provas comuns, com itens elaborados a partir da matriz geral de competências, mas selecionados e readequados visando garantir uma tradução para Libras de qualidade. A videoprova contém os parâmetros psicométricos comuns às demais provas permitindo sua comparabilidade. Além disso, o processo de correção das redações de tais participantes deve passar por aprimoramento.

Os resultados deverão ser depois devidamente analisados, mas pode-se afirmar que a medida, além de incrementar a política de acessibilidade adotada nesse exame, representa uma mudança de paradigma na avaliação de pessoas que têm a Libras como primeira língua, configurando um reconhecimento dos direitos linguísticos da população surda (ROCHA, 2015).

Sua formulação e implementação envolvem desafios de ordem política, conceitual, pedagógica, avaliativa, jurídica, cultural e logística, se constituindo como uma ação de alta complexidade. Emergem debates relativos à construção das provas (matrizes, itens, estrutura, conteúdos, duração da aplicação etc.), às técnicas e estratégias adotadas na tradução de provas em Libras e, ainda, às possibilidades de se considerar, em um exame em larga escala, as realidades educacionais de estudantes com surdez, deficiência auditiva e surdocegeira, entre outras coisas ${ }^{1}$.

\footnotetext{
${ }^{1}$ No ato da inscrição do Enem de 2017, 4.957 pessoas informaram deficiência auditiva e 2.184, surdez. Foram apresentadas 1.897 solicitações de videoprova em Libras e 1.489 de intérprete. Essas cifras poderão sofrer alterações ao longo do processo de confirmação (INEP, 2017).
} 
http://dx.doi.org/10.5902/1984686X28732

O Enem, entre suas finalidades, serve como principal meio de seleção para o ensino superior, e, por isso, a oferta de uma prova em Libras pode ser acompanhada de resistência por parte de setores contrários a políticas de inclusão e ao reconhecimento dos direitos das pessoas com deficiência. O presente artigo busca refletir sobre a necessidade, pertinência e legitimidade do desenvolvimento de instrumentos específicos em Libras e em Português como segunda língua (L2) para a avaliação educacional de tais estudantes no âmbito do Enem, considerando, sobretudo, fatores de ordem jurídica, educacional e pedagógica, com vistas a contemplar o direito à educação de qualidade, o direito à acessibilidade e a equidade nos processos de avaliação.

\section{A educação de surdos e as barreiras em provas a estudantes que têm Libras como primeira língua}

Visando aprofundar o conhecimento teórico e instrumental no campo da Educação de surdos e aprimorar pesquisas e processos relativos à dotação de acessibilidade em seus exames e avaliações, a Diretoria de Avaliação da Educação Básica do Inep (Daeb/Inep) instituiu, em 2012, comissões assessoras de especialistas oriundos em sua maioria de quadros de universidades brasileiras. Uma delas, a Comissão Assessora de Especialistas em Educação Especial e Atendimento Diferenciado no âmbito dos Exames e Avaliações da Educação Básica (doravante, Comissão Assessora em Educação Especial) foi incumbida, principalmente, de subsidiar a Daeb em relação à política de acessibilidade, considerando a diversidade do público da Educação Especial e do Atendimento Diferenciado (mais tarde denominado Atendimento Especializado) (INEP, 2012a)². Recentemente, com o objetivo de viabilizar a tradução e a gravação do Enem em Libras, foi nomeada a Comissão de Assessoramento Técnico-Pedagógico em Língua Brasileira de Sinais da Diretoria de Avaliação da Educação Básica (INEP, 2017)³.

A Comissão Assessora em Educação Especial identificou a necessidade de se eliminarem as barreiras linguísticas interpostas a participantes surdos todos os exames e avaliações do Inep. Sua atuação promoveu a compreensão acerca da necessidade de se avançar e reformular a política de acessibilidade nos exames e avaliações diagnósticas da

\footnotetext{
2 Nos anos seguintes, a comissão sofreu acréscimos e substituições de integrantes (INEP, 2014, 2016).

3 Para uma análise do atendimento especializado no Enem, ver: Junqueira, Martins e Lacerda (2016).
} 
http://dx.doi.org/10.5902/1984686X28732

Educação Básica e a partir de sua atuação ganhou consistência a ideia de, à luz da experiência de outras universidades federais, desenvolver, no Inep, uma prova específica em Libras (COMISSÃO, 2013; ROCHA, 2015).

Os processos de ensino e aprendizagem de surdos e deficientes auditivos estão relacionados à singularidade linguística desse alunado. Duas questões centrais estão na base desses processos. A primeira refere-se a como ensinar a língua portuguesa, de modalidade oral-auditiva, a quem não escuta e, por isso, não a adquire de maneira espontânea na interação com os falantes nativos (MARINHO, 2013a). A segunda diz respeito à apresentação dos diversos conteúdos escolares a partir da Libras, em um cenário nacional no qual grande parte desses alunos matriculados nas redes públicas e particulares é também aprendiz incipiente da Libras (NASCIMENTO, 2013).

O Decreto no 5.626, de 22 de dezembro de 2005 (BRASIL, 2005), entre outras coisas, norteia as ações na área da Educação de Surdos nacionalmente, nos diferentes níveis de ensino. Ele prevê a presença de professores bilíngues (Libras-Português) e a utilização da Libras como língua de instrução na Educação Infantil e no Ciclo I do Ensino Fundamental; e também o ensino da língua portuguesa como L2 para todos os níveis de ensino. A partir do Ciclo II do Ensino Fundamental em diante está prevista, ainda, a presença de intérpretes de Libras para acompanhar os estudantes surdos no acesso aos conteúdos ministrados. Entretanto, o contexto educacional bilíngue encontra-se reduzido ao uso limitado da Libras (por poucos usuários), e quando há necessidade de comunicação imediata com os surdos ou para tornar compreensíveis os textos (orais ou escritos) em português ${ }^{4}$. Fora isso, o ensino da língua portuguesa fundamenta-se, majoritariamente em práticas escolares pensadas para alunos ouvintes, como língua materna. A partir dessas práticas, os professores - alguns pouco bilíngues - têm preparado suas aulas, fazendo ligeiras adaptações no material didático dos ouvintes, na expectativa de ensinar e avaliar também os alunos surdos.

Na última década, assistimos a uma crescente preocupação com o ensino da língua portuguesa como L2 para o alunado surdo. A atenção a esse campo de pesquisa se dá por ser esta língua a base para o acesso a todo o conhecimento escolar disponibilizado pela escrita (LACERDA, SANTOS e MARTINS, 2016). Apesar da preocupação em torno da

\footnotetext{
${ }^{4}$ Esta seria a situação de atendimento básico às necessidades linguísticas dos alunos surdos, prevista por lei. Todavia, este atendimento não vem ocorrendo em muitas escolas nas quais os alunos surdos se encontram matriculados (STROBELL, 2006).
} 
http://dx.doi.org/10.5902/1984686X28732

alfabetização e letramento dos surdos, a literatura nacional especializada ainda traz poucas discussões sobre adequações curriculares ou adaptações metodológicas para o ensino, acompanhamento e avaliação de crianças surdas e deficientes auditivas. Considerando-se as especificidades desse público, a aquisição do português escrito requer uma abordagem peculiar, uma vez que o material sonoro das línguas orais não é - mínima ou plenamente - tangível para eles, razão pela qual a metodologia de ensino de L2 mostra-se a mais apropriada para ensinar-lhes português escrito.

Outros países avançaram nessa área. O Estado Português lançou em 2011 o Programa de Português como Segunda Língua para Alunos Surdos: Ensinos Básicos e Secundários (PORTUGAL, 2011), documento norteador para o ensino da língua, que poderia servir como parâmetro na elaboração de um programa que atenda às necessidades dos surdos e deficientes auditivos brasileiros. Países com maior tradição na Educação de surdos, como a Suécia, também dispõem de documentos oficiais que discutem o ensino de L2 para surdos (SVARTHOLM, 2014).

Sabidamente, os estudantes surdos e deficientes auditivos que chegam ao Ensino Médio das escolas brasileiras apresentam níveis bastante variados de conhecimento tanto em Libras quanto em língua portuguesa (PEDROSO e DIAS, 2011). E com frequência apresentam acentuada defasagem de proficiência em língua portuguesa, sobretudo no que tange à leitura e à produção de textos escritos. Assim, em função da escolaridade ainda bastante precária, muitos alunos surdos concluem o Ensino Médio com um domínio insuficiente da língua portuguesa escrita e dos conteúdos acadêmicos de forma geral.

Cabe ressaltar que a diferente competência linguística entre surdos e deficientes auditivos é acarretada por múltiplos fatores, entre eles: o grau da perda auditiva, a época do surgimento da surdez, a situação socioeconômica, as condições culturais, fatores emocionais e intelectuais, e a forma como é conduzida sua educação escolar. Enfim, tudo aquilo que pode influir no desenvolvimento da linguagem. Porém, o mais importante é a oportunidade de exposição a um contexto linguístico adequado, o mais cedo possível, que alicerce o desenvolvimento dos processos cognitivos e psicossociais.

Nos últimos 10 anos, a crescente adesão de estudantes surdos e deficientes auditivos ao Enem tem mostrado a importância desse exame não apenas como instrumento de avaliação, mas também como uma oportunidade de acesso ao nível superior (INEP, 2015). Em razão desse cenário, é imprescindível, garantir o ajustamento dos critérios 
http://dx.doi.org/10.5902/1984686X28732

diferenciados na aferição da proficiência escrita desses participantes, com a promoção de tratamento isonômico a essa minoria linguística.

No Enem, desde 2012, na correção das provas escritas dos participantes surdos, com deficiência auditiva ou surdocegueira, adotam-se mecanismos de avaliação coerentes com o aprendizado da língua portuguesa como L2. No entanto, a Comissão Assessora em Educação Especial identificou incongruências, fragilidades e insuficiências da atual matriz de correção específica e apontou a necessidade de se aprimorar esse processo, visando a revisão integral da matriz de correção, e a formação das equipes encarregadas pela correção diferenciada (MARINHO, 2013b) ${ }^{5}$.

\section{A tradução e a interpretação Português-Libras em exames e avaliações}

A Lei 10.436/2002 (BRASIL, 2002) e o seu decreto regulamentador, o Decreto 5.626/2005, colocaram as instituições que organizam provas e vestibulares diante da necessidade de adotar providências específicas no campo da avaliação de estudantes surdos ou deficientes auditivos. Em todo o país, está presente o recurso a tradutores e intérpretes de Libras-Português (TILSP) como meio de mediação da comunicação entre surdos e ouvintes ou de surdos. Durante a aplicação do Enem é comum a oferta TILSP.

No entanto, se tal recurso encontra legitimidade e amparo legal, tal estratégia tem limites, especialmente no campo da aplicação de avaliações, exames, concursos e vestibulares. Destacam-se os limites da atuação de TILSP no âmbito das aplicações de provas dada a impossibilidade de acesso prévio às provas, por razões de sigilo e segurança. Além disso, eles precisariam ter pleno domínio dos temas das provas, como também, condições de encontrar a melhor maneira de traduzir não somente trechos, mas toda a prova, quando necessário (ROCHA, 2015).

Além disso, há os desafios inerentes aos trabalhos de tradução/interpretação para Libras em ambientes de prova. O conhecimento profundo das duas línguas, suas nuances e idiossincrasias. A ausência ou insuficiência de conhecimento de terminologia em Libras. A disponibilidade de tempo para refletir sobre a melhor tradução, sem fornecer respostas ou alterar o caráter ou a finalidade do item ou da prova. A necessidade de refletir e trocar

\footnotetext{
${ }^{5} \mathrm{~A}$ experiência de correção diferenciada e as mudanças introduzidas a partir do desenvolvimento da videoprova em Libras no Enem geraram observações e orientações técnicas relativas à correção das redações de participantes surdos, deficientes auditivos e surdocegos (MARINHO, 2017b).
} 
http://dx.doi.org/10.5902/1984686X28732

opiniões com colegas da área e com os responsáveis pela elaboração da prova. As distintas orientações por parte dos coordenadores das unidades de aplicação para a atuação. A maioria dos participantes surdos não atingir a compreensão dos textos escritos em língua portuguesa (MARTINS, 2017; ROCHA, 2015). Em outras palavras: um conjunto de desafios que não podem ser enfrentados ou superados por meio do mero recurso a TILSP em ambientes de prova, o acesso a uma vaga universitária pode estar em jogo, e as condições de trabalho de tais profissionais são bastante complicadas. Como observa Rocha (2015), a impossibilidade de superação de tais desafios representa, por si só, a interposição de uma barreira ao bom desempenho de participantes surdos ou deficientes auditivos em qualquer prova, exame ou avaliação.

Ademais, o Inep observa um baixo desempenho desse público em exames e avaliações, especialmente no Enem (INEP, 2015) ${ }^{6}$. O Instituto se vê, assim, obrigado a considerar possíveis elementos que representam ulteriores barreiras ao desempenho desses participantes. Neste sentido, a simples garantia da presença de TILSP durante as aplicações não garante a acessibilidade necessária e indispensável ao participante.

Cabe, ainda, assegurar o atendimento profissional de tradução/interpretação de idêntica qualidade a todos os surdos atendidos no âmbito de um exame ou avaliação, de modo a assegurar equidade e isonomia. No entanto, aos problemas elencados somam-se outros. A profissionalização de TILSP é recente em todo o país (Lei no 12.319/2010) (BRASIL, 2010), e estudos demonstram que a formação deste profissional tem se dado de maneira superficial, constituindo um fator que pode comprometer o desempenho de pessoas surdas nos exames, avaliações e concursos (PEREIRA e FRONZA, 2007). Além disso, constata-se uma desigual distribuição territorial de tais profissionais. Não por acaso, tais dificuldades têm sido detectadas na realização do Enem e outros exames e avaliações.

Diante desse quadro, em 2013 a Federação Nacional de Educação e Integração dos Surdos (Feneis) encaminhou ao Inep um conjunto de reivindicações, entre as quais se destaca a disponibilização imediata de provas de Português confeccionadas como L2 e provas individuais das demais disciplinas traduzidas em Libras, em meio digital, em todos os seus exames e avaliações, e a consequente eliminação da figura do TILSP como principal mediador entre o participante e a prova.

\footnotetext{
${ }^{6} \mathrm{~A}$ cada edição do Enem, constatava-se que os participantes surdos apresentavam as mais baixas médias entre as pessoas com deficiência, apenas comparáveis àqueles com os baixos níveis socioeconômicos (INEP, 2015).
} 
http://dx.doi.org/10.5902/1984686X28732

Vale reiterar que a interpretação Português-Libras em situações de provas enfrenta fatores que comprometem a qualidade da interpretação fornecida pelos profissionais, independentemente da qualidade da formação, certificação ou de sua atuação. Assim, para garantir equidade aos participantes e isonomia aos exames, é preciso que o profissional TILSP deixe de ser o principal mediador entre esses participantes e a prova. Ele continuará necessário, no entanto, não mais para auxiliar na execução da prova, mas para garantir a comunicação entre surdos e ouvintes ou para auxiliar no atendimento de necessidade eventual não relacionada à resolução de itens específicos da prova.

\title{
Fundamentos jurídicos dos exames em Libras e Português como segunda língua
}

Além do conjunto de marcos jurídicos nacionais e internacionais que reconhecem os direitos comunicacionais e educacionais da comunidade surda, é preciso também considerar determinações legais que, favorecem a adoção de mecanismos avaliativos em Libras registrados em vídeo ou outro meio eletrônico ou tecnológico. Tal medida aparece pela primeira vez, no Brasil, registrada no artigo 14 do Decreto 5.626/2005 (BRASIL, 2005), que também trata do uso e da difusão da Libras e da língua portuguesa para o acesso das pessoas surdas à educação.

O Conselho Nacional dos Direitos da Pessoa com Deficiência produziu a Recomendação nº 001, de 15 de julho de 2010 (CONSELHO, 2010), por meio da qual:

\begin{abstract}
Recomenda que os editais de concursos públicos contemplem o princípio da acessibilidade para garantir a igualdade de condições à pessoa surda ou com deficiência auditiva, como os demais candidatos, determinando expressamente medidas indispensáveis para remoção de barreiras que impeçam a plena e livre concorrência, sem prejuízo de outras que porventura venham a ser adotadas.
\end{abstract}

Em relação à língua, reconhece a Libras 'como meio legal de comunicação e expressão de natureza visual-motora, com estrutura gramatical própria, constituindo sistema linguístico de transmissão de ideias e fatos' (Art.1); quanto a inscrição prevê que os editais sejam bilíngues, com a presença de vídeo em Libras. Afirma que o sistema de inscrição deve prever opções em que o candidato surdo ou com deficiência auditiva realize suas provas (objetivas, discursivas e/ou de redação), em Libras; e que no ato da inscrição, possa solicitar o auxílio de TILSP, independentemente da forma de aplicação das provas e/ou solicitar tempo adicional (CONSELHO, 2010).

Ainda, no que tange a aplicação de provas objetivas, discursivas e/ou de redação, a Recomendação afirma que as provas devem ser aplicadas em Libras, com recursos visuais, 
http://dx.doi.org/10.5902/1984686X28732

por meio de vídeo ou outra tecnologia análoga, seguindo as normas técnicas vigentes. $E$ em relação aos critérios de avaliação afirma que desde o edital devem estar explícitos os mecanismos e critérios de avaliação das provas discursivas e/ou de redação dos candidatos surdos ou com deficiência auditiva, valorizando o aspecto semântico e reconhecendo a singularidade linguística da Libras.

Considera, ainda:

Art. $4.2[\ldots]$ que a pessoa surda educada na língua de sinais, necessariamente sofrerá influências desta na sua produção escrita, tornando necessário o estabelecimento de critérios diferenciados de correção de provas discursivas e de redações, a fim de proporcionar tratamento isonômico aos candidatos surdos (CONSELHO, 2010).

E nesse sentido, prevê também que as provas de redação e/ou discursivas, aplicadas a pessoas surdas ou com deficiência auditiva, deverão ser avaliadas por profissionais qualificados para tal.

Ainda, a Lei no 13.146, 6 de julho de 2015, a Lei Brasileira de Inclusão da Pessoa com Deficiência (BRASIL, 2015), dispõe:

Art. 30. Nos processos seletivos para ingresso e permanência nos cursos oferecidos pelas instituições de ensino superior e de educação profissional e tecnológica, públicas e privadas, devem ser adotadas as seguintes medidas:

I - atendimento preferencial à pessoa com deficiência nas dependências das Instituições de Ensino Superior (IES) e nos serviços;

II - disponibilização de formulário de inscrição de exames com campos específicos para que o candidato com deficiência informe os recursos de acessibilidade e de tecnologia assistiva necessários para sua participação;

III - disponibilização de provas em formatos acessíveis para atendimento às necessidades específicas do candidato com deficiência;

IV - disponibilização de recursos de acessibilidade e de tecnologia assistiva adequados, previamente solicitados e escolhidos pelo candidato com deficiência;

V - dilação de tempo, conforme demanda apresentada pelo candidato com deficiência, tanto na realização de exame para seleção quanto nas atividades acadêmicas, mediante prévia solicitação e comprovação da necessidade;

VI - adoção de critérios de avaliação das provas escritas, discursivas ou de redação que considerem a singularidade linguística da pessoa com deficiência, no domínio da modalidade escrita da língua portuguesa;

VII - tradução completa do edital e de suas retificações em Libras.

Ficam evidentes tanto a obrigação do Estado em garantir a acessibilidade linguística aos participantes surdos e deficientes auditivos, quanto o amparo legal à realização e a 
http://dx.doi.org/10.5902/1984686X28732

aplicação individualizada de provas em vídeos ou outros meios eletrônicos em Libras, bem como de provas específicas para aferir competências e habilidades em L2, no âmbito de exames e avaliações.

\section{Teoria da Resposta ao Item e acessibilidade em exames e avaliações}

Nacional e internacionalmente, a Teoria da Resposta ao Item (TRI) vem sendo crescentemente utilizada em processos em que testes educacionais padronizados são aplicados em grande escala com vista a avaliar habilidades e conhecimentos (ANDRADE, TAVARES e VALLE, 2000; PASQUALI, 2003). No Enem, emprega-se a TRI desde a edição de 2009, sem que isso configure um obstáculo para a adoção de qualquer medida de acessibilidade.

O fato de os itens serem pré-testados, analisados, calibrados a partir de aplicações realizadas com públicos sem deficiência, sem qualquer adaptação ou adequação, deve ser objeto de discussões mais detidas e aprofundadas. No entanto, tal fato não serve para justificar a exclusão das pessoas com deficiência do exame nem tampouco justificaria a oferta limitada de recursos e serviços de acessibilidade.

É preciso considerar que, sem acessibilidade devida, os itens podem ter suas características psicométricas alteradas durante a aplicação, por exemplo, por apresentar linguagem, características ou conteúdos incongruentes com a educação de surdos. Somese a isso uma eventual atuação inconsistente por parte de um TILSP. São situações que, além de representar uma interferência que incide para adulterar o resultado esperado, prejudica a média do participante, não só pelo erro em um determinado item, mas o que esse erro pode representar no conjunto de acertos e erros.

Diferentemente da Teoria Clássica dos Testes, na TRI o cálculo da média leva em consideração a distribuição de acertos e erros atrelada às probabilidades dos desempenhos dos participantes segundo suas proficiências. Dito de maneira esquemática: se 0 participante errar um item cujas probabilidades de acertos são altas inclusive entre participantes com mais baixa proficiência (ou seja, um item considerado "fácil") e, ao mesmo tempo, acertar um item "mais difícil", ele terá uma média final menor do que se tivesse sido o contrário, ou seja, acertado o "fácil" e errado o "difícil". Do mesmo modo, um item considerado a priori "fácil", uma vez dotado de insuficiente acessibilidade se torna, na prática, "difícil", sem que isso seja considerado no momento do cálculo das médias. A mera 
http://dx.doi.org/10.5902/1984686X28732

diferença na atuação dos intérpretes durante o exame pode implicar uma interferência dos desempenhos dos participantes surdos, impactando no cômputo geral de suas médias.

Por conseguinte, a adoção da TRI no exame obriga seus formuladores a buscar soluções que eliminem barreiras que, além de violar direitos, alteram o comportamento psicométrico dos itens e prejudicam as médias obtidas. Em outras palavras: em vez de a TRI representar um empecilho à acessibilidade, o seu emprego é um fator que obriga a buscar a construção de instrumentos mais equitativos, equânimes, sem barreiras em sua concepção pedagógica, formulação, aplicação e análise.

\section{Recomendações em relação às videoprovas em Libras e em Português como segunda língua}

A Comissão Assessora em Educação Especial ressaltou a necessidade de se levar em conta a maneira como o aluno surdo aprende a escrever, defendendo que o ideal seria construir uma matriz específica do Português como L2 e dela decorrem itens específicos (MARINHO, 2013b). Apresentou ainda recomendações com vistas a orientar o Inep a adotar mecanismos para garantir equidade e devida acessibilidade a participantes surdos ou com deficiência auditiva, entre outros, em todos os seus exames e avaliações (COMISSÃO, 2012, 2013a, 2013b). Dentre tais documentos, vale destacar a Recomendação n. 38, de 11 de março de 2013, que, entre diversas orientações e recomendações quanto a diferentes aspectos do atendimento especializado, também dispõe sobre a necessidade de se garantir acessibilidade desde a elaboração de edital e Enem em Libras: Garantir, junto ao Inep, medidas para viabilizar a elaboração de uma versão do Exame em Libras, disponível em versão digital com uso de computadores individuais (COMISSÃO, 2013a, p. 3).

Portanto, a solução mais ágil e equitativa, a disponibilização de provas de língua portuguesa como L2, bem como a tradução e a gravação das videoprovas em Libras em todos os instrumentos de medida adotados no âmbito dos exames e avaliações da Educação Básica, impõe-se como o modo mais apropriado de se assegurar condições de acessibilidade às pessoas surdas ou deficientes auditivas sinalizadoras e, ao mesmo tempo, a oferta de material de divulgação em formatos acessíveis, com a mesma qualidade, para todas elas.

Ao lado disso, é necessário sublinhar que a disponibilização de videoprovas traduzidas em Libras e de provas em Português como L2 possui outras implicações que 
http://dx.doi.org/10.5902/1984686X28732

precisam ser consideradas: manter a obrigatoriedade da oferta de toda a prova impressa em português (inclusive da parte traduzida em Libras); a disponibilização de intérpretes (conforme discutido anteriormente).

Por uma questão de equidade e pela necessidade de assegurar a mesma tradução a todos o que dela necessitam, será preciso deixar claro nos editais dos exames e avaliações que participantes surdos ou deficientes auditivos que tiverem dispensado a prova em Libras e Português como L2 assumirão, automaticamente, não precisar de apoio de TILSP na compreensão do exame ou avaliação e, por conseguinte, somente poderão contar com o apoio para a mediação da comunicação entre eles e os ouvintes.

Dadas as características e as proporções de exames e avaliações como Enem, a sua produção em Libras e Português como L2 representa desafios pedagógicos e logísticos. Assim, a referida Comissão, ressaltou ser importante garantir que a produção das provas em Libras e Português como L2 fosse antecedida de estudos e análises visando qualidade, respeito aos princípios pedagógicos e às finalidades de cada exame e avaliação, bem como questões concernentes a sigilo e segurança.

Por conseguinte, em 2016, o Inep celebrou um acordo com a Universidade Federal de Santa Catarina para a realização de um estudo sobre a viabilidade de ofertar futuras edições do Enem em Libras. Disso resultou uma pesquisa cujas conclusões estão expressas em relatório específico (UFSC, 2016). Com base nos apontamentos deste relatório foi produzida, com a colaboração da Daeb, a Análise Técnica para subsidiar o estabelecimento de critérios gerais e específicos para a seleção de itens para compor as videoprovas em Libras e de língua portuguesa como L2 no Exame Nacional do Ensino Médio (MARINHO, 2017a).

A partir desses produtos, o Inep selecionou e submeteu à análise, tradução e gravação da prova em Libras, que ficou sob a responsabilidade da Comissão de Assessoramento Técnico-Pedagógico em Língua Brasileira de Sinais da Diretoria de Avaliação da Educação Básica. Desse trabalho, além das provas em Libras resultarão relatórios técnicos a serem futuramente divulgados.

Por fim, cabe ainda lembrar que a Comissão Assessora em Educação Especial chama a atenção para a necessidade de o Inep avançar nos estudos, discussões e providências relativas à avaliação de línguas modernas para candidatos usuários de Libras e dotação de acessibilidade para todos os tipos de deficiência. 


\section{À guisa de encerrar}

O Inep encontra-se diante da necessidade de buscar maiores subsídios e investir na aquisição de base de conhecimento para prover-se de matrizes específicas e, no caso do atendimento a pessoas surdas e deficientes auditivas, instrumentos de medida em Libras e Português como L2 e, além disso, manter-se sintonizado com discussões e políticas de uma área muito sensível e estratégica na construção de um modelo de inclusão educacional que assegure educação de qualidade a todas as pessoas.

A lei define a Libras como língua de direito, meio de comunicação e expressão da comunidade surda e dispõe que estudantes surdos devem receber sua formação educacional em Libras como língua primeira e aprender a língua portuguesa como L2 na modalidade escrita, desde o Ensino Fundamental. É indispensável, portanto, que provas e exames considerem as especificidades desse percurso formativo. A disponibilização de videoprovas em Libras e de provas em Português como L2 contempla a especificidade linguística da comunidade surda e a natureza sui generis de seu processo de escolarização e de aquisição de habilidades e competências.

É importante reter que submeter um surdo que tem a Libras como primeira língua a uma prova com profundas marcas de Português como primeira língua equivale a colocá-lo em situação de desvantagem em relação aos ouvintes e pode representar uma quebra de isonomia no exame. Também pode comprometer os parâmetros psicométricos da prova e ferir a isonomia do exame a disponibilização de intérpretes como recurso principal de acessibilidade às provas.

A disponibilização de videoprovas em Libras e de provas em Português como L2 não configura privilégio indevido e nem tampouco fere a isonomia do exame. Pelo contrário, é meio justo, seguro e certo para assegurar direitos, garantir equidade e manter a isonomia do exame. Nessa perspectiva, a aplicação da versão em Libras do Enem em muito interessa para que, a partir da análise da aplicação e das médias, se possa aprofundar a reflexão e seguir na busca de formas de acessibilidade aperfeiçoadas para esse público, assumindo uma mudança de paradigma. 
http://dx.doi.org/10.5902/1984686X28732

\section{Referências}

ANDRADE, D. F.; TAVARES, H. R.; VALLE, Raquel da C. Teoria da Resposta ao Item: conceitos e aplicações. São Paulo: Associação Brasileira de Estatística, 2000.

BRASIL. Lei n. 10.436, de 24 de abril de 2002. Dispõe sobre a Língua Brasileira de Sinais Libras e dá outras providências.

BRASIL. Decreto n. 5.626, de 22 de dezembro de 2005. Regulamenta a Lei n. 10.436, de 24 de abril de 2002, que dispõe sobre a Língua Brasileira de Sinais - Libras, e 0 art. 18 da Lei n. 10.098, de 19 de dez. 2000.

BRASIL. Decreto n. 6.949, de 25 de agosto de 2009. Promulga a Convenção Internacional sobre os Direitos das Pessoas com Deficiência e seu Protocolo Facultativo.

BRASIL. Lei n. 12.319, de $1^{\circ}$ de setembro de 2010. Regulamenta a profissão de tradutor e intérprete de Libras.

BRASIL. Lei n. 13.005, de 25 de junho de 2014. Aprova o Plano Nacional de Educação.

BRASIL. Lei n. 13.146, de 6 de julho de 2015. Institui a Lei Brasileira de Inclusão da Pessoa com Deficiência (ou Estatuto da Pessoa com Deficiência).

COMISSÃO ASSESSORA DE ESPECIALISTAS EM EDUCAÇÃO ESPECIAL e atendimento diferenciado em exames e avaliações da educação básica. Recomendação n. 37. Brasília, Inep, 2012.

COMISSÃO ASSESSORA DE ESPECIALISTAS EM EDUCAÇÃO ESPECIAL e atendimento diferenciado em exames e avaliações da educação básica. Recomendação n. 38. Brasília, Inep, 2013a.

COMISSÃO ASSESSORA DE ESPECIALISTAS EM EDUCAÇÃO ESPECIAL e atendimento diferenciado em exames e avaliações da educação básica. Proposta de matriz de referência para a Avaliação Nacional da Alfabetização de alunos surdos e deficientes auditivos. Brasília, Inep, 2013b.

CONSELHO NACIONAL DOS DIREITOS DA PESSOA COM DEFICIÊNCIA. Recomendação n. 001, de 15 de julho de 2010 (Recomendação para garantir a aplicação do princípio da acessibilidade à pessoa surda ou com deficiência auditiva em concursos públicos, em igualdade de condições com os demais candidatos). Brasília: Presidência da República, Secretaria de Direitos Humanos, Conade, 2010.

CONVENÇÃO sobre os Direitos das Pessoas com Deficiência: Protocolo Facultativo à Convenção sobre os Direitos das Pessoas com Deficiência: decreto legislativo n. 186, de 09 de julho de 2008: Decreto n. 6.949, de 25 de agosto de 2009. 4. ed., rev. e atual. Brasília: Secretaria de Direitos Humanos, Secretaria Nacional de Promoção dos Direitos da Pessoa com Deficiência, 2011.

INEP. Portaria n. 252, de 20 de julho de 2012a. (Institui a Comissão Assessora de Especialistas em Adaptação de Provas e Itens para Exames e Avaliações da Educação Básica). 
http://dx.doi.org/10.5902/1984686X28732

INEP. Portaria n. 253, de 20 de julho de 2012b. (Institui a Comissão Assessora de Especialistas em Educação Especial e Atendimento Diferenciado no âmbito dos Exames e Avaliações da Educação Básica).

INEP. Portaria n. 438, de 9 de setembro de 2014. (Institui a Comissão Assessora em Educação Especial e Atendimento Especializado no âmbito dos Exames e Avaliações da Educação Básica).

INEP. Portaria n. 150, de 4 de abril de 2016. (Institui a Comissão Assessora para a Adaptação de Provas e Itens para Exames e Avaliações da Educação Básica).

INEP. Portaria n. 397, de 12 de maio de 2017. (Institui a Comissão de Assessoramento Técnico-Pedagógico em Língua Brasileira de Sinais da Diretoria de Avaliação da Educação Básica).

INEP. Relatório Pedagógico: Enem 2011-2012. Brasília: Inep, 2015.

INEP. Videoprova Traduzida em Libras será aplicada para 1,9 mil participantes do Enem 2017. Brasília: Inep, Assessoria de Comunicação Social, 2017. Disp. em: http://portal.inep.gov.br/artigo/-/asset_publisher/B4AQV9zFY7Bv/content/videoprovatraduzida-em-libras-sera-aplicada-para-1-9-mil-participantes-do-enem-2017/21206. Acesso e $12 / 06 / 2017$.

JUNQUEIRA, R. D.; MARTINS, D. A.; LACERDA, C. B. F de. Política de Acessibilidade e Exame Nacional do Ensino Médio (Enem). Educação \& Sociedade, Campinas, v. 38, n. 139, p. 453-471, 2017.

LACERDA, C. B. F. de; SANTOS, L. F. dos; MARTINS, V. R. de O. (orgs.). Escola e Diferença: caminhos da educação bilíngue para surdos. São Carlos: Edufscar, 2016.

MARINHO. M. L. Matriz de referência e adaptação dos instrumentos da Avaliação Nacional da Alfabetização (ANA) para atendimento aos participantes com surdez e deficiência auditiva. Reflexão crítica e proposições de medidas e critérios sobre a produção de Matriz de referência e adaptação da prova de Português para os participantes surdos e deficientes auditivos, no processo de Avaliação Nacional da Alfabetização. Brasília, Inep, 2013a.

MARINHO. M. L. Projeto de análise da matriz de correção das redações dos participantes surdos e deficientes auditivos no Exame Nacional do Ensino Médio (Enem). Relatório técnico. Brasília, Inep, 2013b.

MARINHO. M. L. Análise técnica para subsidiar o estabelecimento de critérios gerais e específicos para a seleção de itens para compor as videoprovas em Libras e de Língua Portuguesa como segunda língua no Exame Nacional do Ensino Médio. Relatório técnico. Brasília, Inep, 2017a.

MARINHO. M. L. Análise técnica para subsidiar a revisão da Matriz de correção das redações dos participantes surdos e deficientes auditivos no Exame Nacional do Ensino Médio. Relatório técnico. Brasília, Inep, 2017b. 
http://dx.doi.org/10.5902/1984686X28732

MARTINS, D. A. O Enem como via de acesso do surdo ao ensino superior brasileiro. Tese (Doutorado). São Carlos: Universidade Federal de São Carlos, 2017.

NASCIMENTO, S. P. do. Relatório com reflexão analítica sobre a produção em Língua de Sinais Brasileira (Libras) da prova de Matemática da Avaliação Nacional da Alfabetização (ANA) 2013. Relatório técnico. Brasília, Inep, 2013.

PASQUALI, L. Psicometria: teoria dos testes na psicologia e na educação. 2. ed. Petrópolis: Vozes, 2003.

PEDRoso, C. C. A. e DIAS, T. R. S. Inclusão de alunos surdos no ensino médio: organização do ensino como objeto de análise. Nuances: estudos sobre Educação, Presidente Prudente, v. 19, n. 20, p. 134-154, 2011

PEREIRA, Maria C. P.; FRONZA, Cátia de A. Estudo sobre a proficiência lingüística do intérprete de libras. Cadernos do Congresso Nacional de Linguística e Filologia (CNLF), v. XI, n. 9, Rio de Janeiro: Pragmática, 2007.

PORTUGAL. Ministério da Educação. Programa de português L2 para alunos surdos: ensinos básicos e secundários. Lisboa, 2011.

ROCHA, L. R. M. da. O que dizem surdos e gestores sobre vestibulares em Libras para ingresso em universidades federais. Dissertação (Mestrado). Universidade Federal de São Carlos, 2015.

STROBEL, K. L. A visão histórica da in (ex)clusão dos surdos nas escolas. ETD-Educação Temática Digital, Campinas, vol. 7, n. 2, p. 245-254, 2006.

SVARTHOLM, K. 35 anos de educação bilíngue de surdos - e então? Educar em Revista, Curitiba, ed. esp. n. 2, p. 33-50, 2014.

UFSC. Estudo Preliminar para o Enem em Libras. Relatório Técnico. Florianópolis, Departamento de Artes e Libras - DALi/CCE/UFSC, dez. 2016.

\section{Correspondência}

Rogério Diniz Junqueira - Instituto Nacional de Estudos e Pesquisas Educacionais Anísio Teixeira (Inep), Setor de Indústrias Gráficas, SIG Quadra 4 Lote 327, CEP: 70610-908. Brasília, Distrito Federal, Brasil.

This work is licensed under a Creative Commons Attribution-NonCommercial 4.0 International (CC BY-NC 4.0) 